\title{
Development of a Virtual Learning Environment based on Gamefication to Improve Mathematical Concepts and Skills for Deaf Students
}

\author{
S.M. El Atawy \\ Dept. of Computer Science \\ Faculty of Specific Education \\ Damietta University, Egypt
}

\begin{abstract}
In education in recent times, especially during the outbreak of Covid 19, the interest of education professionals has become to search for the most appropriate ways to use technology as a motivational tool in education. The use of gamification in education is very important because it works to arouse students' interest and reduce learning time. The current study aims to determine the effects of applying a virtual learning environment based on gamification on improving the achievement and practical skills of deaf students in mathematics at the primary stage in Egypt. Java, JavaScript, , PHP, CSS, HTML, MSQL, and AppServ, are used to develop the application. The study followed the quasi-experimental research method. The application was applied to students from Al-Amal School for the deaf and hard of hearing in Damietta - Egypt. The study used two tools: an achievement test, and a test of practical skills in mathematics after rationing. The value of the reliability test was more than 0.89 . The t-test was used to analyze the students' scores in the preand post-test, and the two null hypotheses were tested at the significance level of 0.05 . The results showed the effectiveness of the virtual learning environment based on gamification in developing the achievement and practical skills of deaf students in mathematics.
\end{abstract}

\section{General Terms}

Gamefication, Virtual learning environment.

\section{Keywords}

Virtual learning environment; adaptive learning environment; mathematic concepts; mathematic skills; deaf students. Gamefication

\section{INTRODUCTION}

The use of virtual learning environments (VLEs) allows students to collaborate, exchange ideas, and use distinct technologies that increase motivation to learn [1]. Using VLEs is not just a way to manage course content, it also helps teachers schedule a range of educational activities, which increases interaction between teachers, students, and educational materials [2]. The use of VLEs helps transfer knowledge among students regardless of the media they are used [3]. number of studies indicate a low achievement of deaf students in mathematics, as research studies indicate that deaf children lag behind their peers who hear from ( 2 to 3.5 years) in mathematics achievement tests [4]. Deaf people are defined, according to the World Health Organization, as lack or a complete loss of hearing [5] . Communication with deaf individuals is through sign language[6]. It is a visual and spatially organized language [7], this doesn't mean that all deaf students should study mathematics by focusing on sign language. Rather, attention must be paid to the way of curriculum introduces mathematics, especially as it turns out that deaf who using sign language have the ability to think spatially better than hear people $[8,9]$. despite the increase in the number of deaf students enrolled in school, there is evidence indicating that poor study habits may lead the deaf to drop out of school[10]. this leads to the difficulty of their transition to the work, especially for who don't have the opportunity to obtain more education [11]. Education experts believe that it is necessary to use information technology's to improve the teaching and learning process through the development of new learning methods[12,13]. in the field of mathematics learning, practical activities are an essential part of any mathematics curriculum because they enhance mathematical concepts, especially with deaf student, for this reason there is a need to create teaching and learning methods that push students to effective learning and create a new virtual spaces to enhance practical activities $[14,15]$. These spaces are called virtual learning environments. VLEs can be effective in education as they can be used to create chat rooms, forums, web conferences, e-mails, Free short message service (sms), share audio recordings and educational videos, and thus develop educational and social interactions through synchronous and asynchronous communication $[16,17]$. Any educational system is based on a student, teacher, environment, and curriculum. The curricula in Egypt depend on memorization and indoctrination, so , the educational system face a number of problems, including the inability to motivate students and invest their talents and abilities, then, this causes a weak motivation among students to learn[18]. Therefore, teachers face many challenges, the most important of which is how to adapt students 'learning towards the needs and requirements of students. Teachers should use teaching methods that make students active participants in learning[19]. Educational games are a promising trend to motivate students towards learning[21] . based on [22] Gamification is defined as the use of game design elements in non-game contexts. It is also defined as the use of fun elements found in games and appiyingthem in real activities[23]. The difference between gamification and games is that the first applies the principles of the game in normal activities and it does not necessarily create a game [24]. The use of educational games is a promising approach in education to their ability to enhance knowledge and skills. But creating an educational game is difficult, expensive, needs a long time, and it is achievement the goals selected by the game designer, while gamification uses thinking approach in games and game design elements to motivate students and increase their participation in learning [25]. The summative assessment is used after teaching to give judgments about the certificates and the progress of the level, while the formative 
assessment is used during the teaching to find out and correct weaknesses and provide feedback to students during the learning process [26]. Today's curriculum rely on information and communication technology, then, assessment and exams will inevitably become digital[20]. Therefore, using Gamification, students can pass difficult tasks in a short time, as well as analyze the mistakes they make and benefit from their causes in correcting mistakes. [27]. This work aims to develop an VLE based on gamification using JavaScript, Java, PHP, CSS, HTML, MSQL, and AppServ, the VLE that will support the learning environment in primary schools for hearing-impaired students, it will allow students to learn anytime and anywhere, communicate with teachers, and compete with classmates. We will study its effectiveness in developing the cognitive and skill aspects in mathematics for deaf students.

\section{LITERATURE REVIEW}

\subsection{Virtual Learning Environment for deaf}

Virtual learning environments are defined as the environment which learning is by the use of electronic media when the teacher and student are far from each other in time and place and that includes different media of data, video and sound [28]. There are some studies that use VLE for deaf learning, Matjaž Debevc, and, et al (2010) presented basic guidelines of e-learning for deaf and directions for design of e-learning sites accessibility [29]. Debevc, M., Stjepanovič, Z., \& Holzinger, A (2014) improved an adaptive e-learning environment in computer literacy for deaf and hard of hearing people, This course is based on the learning management system Moodle, and included streaming video with sign language translator video. usig two methods to analyze and confirmed The usability of the e-learning course : the Software Usability Measurement Inventory (SUMI) evaluation method, and, the Adapted Pedagogical Index (AdaPI), The results showed the suitability of the e-learning course for the target group [30]. Adamo-Villani, N., Carpenter, E., \& Arns, L. (2006) presented the 3D learning environment to improve mathematical skills and conceptsto deaf students, through interaction with 3D virtual signers and environments. The application includes a gesture control system, and can be showed in devices which generating a three-dimensional image [31]. Also Chee Kyun $\mathrm{Ng}$ et al. (2008) presented an $e_{-}$learning system that allows communication between normal students and students who are blind, deaf, and those with physical disabled. The system focused on communicating deaf students with normal students and the teacher through chat-rooms, while it focused on the blind students communicating with others using voice over the Internet. As for students with limited mobility, their communication was by allowing them to attend the classroom from home via the Internet. One of the advantages of this system was that it reduced the educational gap between normal students and students with disabilities, however, needed training on its use [39]. Hashim, M. H. M., \& Tasir, Z. (2020) presented A questionnaire-based research was presented to examine the usability of e-learning environments containing academic presentations and sign language videos. The results showed that deaf students who achieved the best performance increase category were those who accessed sign language videos most frequently[40].

\subsection{Gamification in Education System}

Shohieb, S. M. (2019) presented an e -learning system for teaching mathematics, to deaf students Arab. The application included different gamification components to motivate the deaf students . This program is supported with an Arabic Sign Language (ArSL), using acting avatar. The results showed that the proposed framework takes into account the psychological needs of users, However, this system focused on the use of gamification techniques [32]. Yigal and Meirav (2015) In a set of studies, they examined the effects of the points as a main element of gamification, on performance in basic mathematics concepts. They found good results that promote motivation and engagement of students especially those of grades 6-8 [33]. Adeniyi, S., \& Kuku, O. (2020) presented a study to desplay the impact of experiential learning and gamification on achievement in mathematics for hearing impairment learners. This study used Mathematics Knowledge Check (MKC) to collect , and analyzed data. the results found out that using experiential learning methods and gamification were of benefit to hearing impairment learners [34]. Chebotareva, I., Pashutina, O., \& Makhova, V. (2020) presented application based on gamification for Law students. the results desplayed that the use of gamification in the learning process of law students increased broadens their outlook, proactive capacity in obtaining knowledge, revising information and interest in learning new material[35]. also Bidarra, $\mathrm{J}$ and et al (2015) studied the effect of utilizing gamification of content and game design to learning Portuguese sign language interactive and enjoyable. this study depended on involve students in learning specific subjects using gamification approach supported by ICT based tools. The results showed that gamification can be added to ICT-based tools to improve learning processes so that the acquired knowledge becomes more memorable [36]. Gafni, Achituv, Eidelman and Chatsky (2018) presented A study investigating The use of gamification in e-learning platforms and its impact on student learning The results of the study showed that the students who studied through the electronic platforms that include the elements of gamification were enthusiastic to continue learning and showed high achievement in learning [37].also Jagušt, T., Boticki, I., Mornar, V., \& So, H. J. (2017) presented using gamification in digital lessons for students who learning mathematics in primary schools in Croatia. Gamification extensions and algorithms were designed to integrated in digital lessons to improve engagement and motivation of young learners' in math learning. The results desplay that gamification increases students' interest towards learning compared to the non-gamified approach [38].These results illustrate the importance of using gamification in learning processes. Through the foregoing, it is clear that that both the virtual learning environments and the use of the gamification strategy have proven their effectiveness in learning and achievement of students. To our knowledge, there is no system available that uses virtual learning environments based on Gamification techniques to build an educational system to educate Deaf Arab students. so It is necessary to test the effectiveness of using virtual learning environments based on the strategy of gamification in the learning process of students with hearing disabilities. Therefore, this study evaluates the use of virtual learning environments based on the gamification of mathematics achievement among students with a hearing impairment.

\subsection{Research Problem and Questions}

According to the World Federation of the Deaf (WFD), in addition to the results of a number of researches (Shohieb et al. 2009; Abo El-Soud, Shohieb 2010; Shohieb 2016, Shohieb 2019 ; Riad et al. 2013; Riad et al. 2014) they indicated that about $80 \%$ of the deaf educated are considered semi-literate in addition to (Adeniyi \& Kuku ،2018 ; Tanridiler, Uzuner \& 
Girgin, 2015 ; Shelton \& Parlin, 2016; Kritzer , 2005) they indicated to the low achievement of deaf students in mathematics, and mathematics learning was documented as difficult, These results may be due to several reasons, including:

The use of traditional methods in teaching, no using technology, interactive and fun to help students learn mathematics, and accordingly research questions were asked to address the goal of this study as follows:

1. What are the effects of a Virtual Learning Environment based on gamefication of deaf student achievement in a mathematics course at primary school ?

2. What are the effects of a Virtual Learning Environment based on gamefication of the mean scores in pretest and post test of the experimental group.

\section{METHODOLOGY}

\subsection{The Proposed System design}

The iterative model was used in the design of the program, this model allows overlapping the stages of planning, design and development, which provides the opportunity to accommodate the changes that occur even in the course of implementation. Stakeholders in VLEMD are Teachers, Deaf Students, and Administrators Figure 1 illustrates a use case diagram for VLEMD. which Describes the role of each of users in achieving the specific learning objectives.

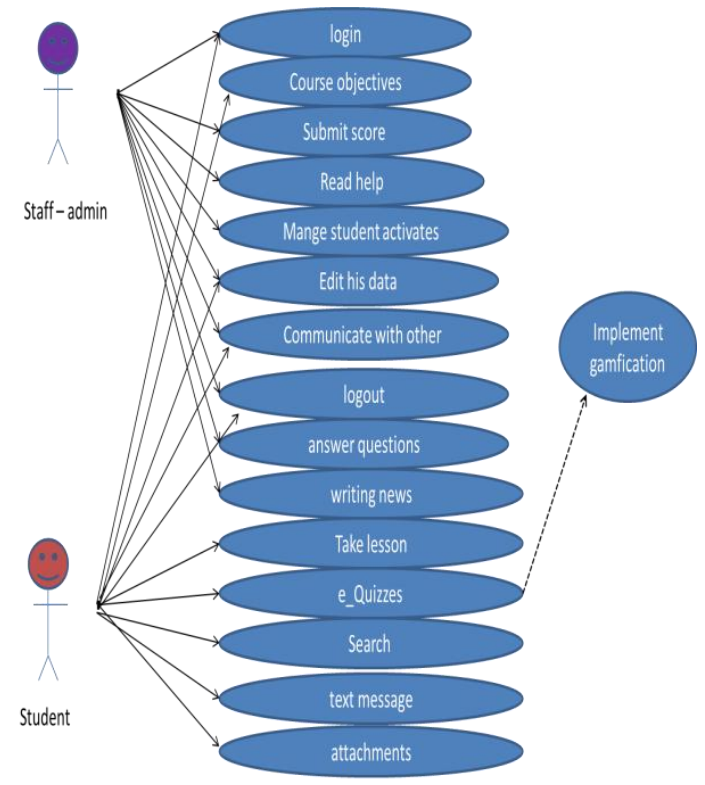

Fig. 1. Use-case diagram for VLEMD

While the figure 2 illustrates the workflow of the VLEMD.

\subsubsection{Roles of student}

While the student's roles include: modifying his data, studying the contents of the lessons, following up on the published news from the teacher, reading instructions on using the environment in learning, performing quizzes, communicating with the teacher and with colleagues through e-mail, chat or forum, and Performing activities by raising the required assignments, view the results of his quizzes, and use the search engine to search for the information he needs in the learning environment throw the internet.

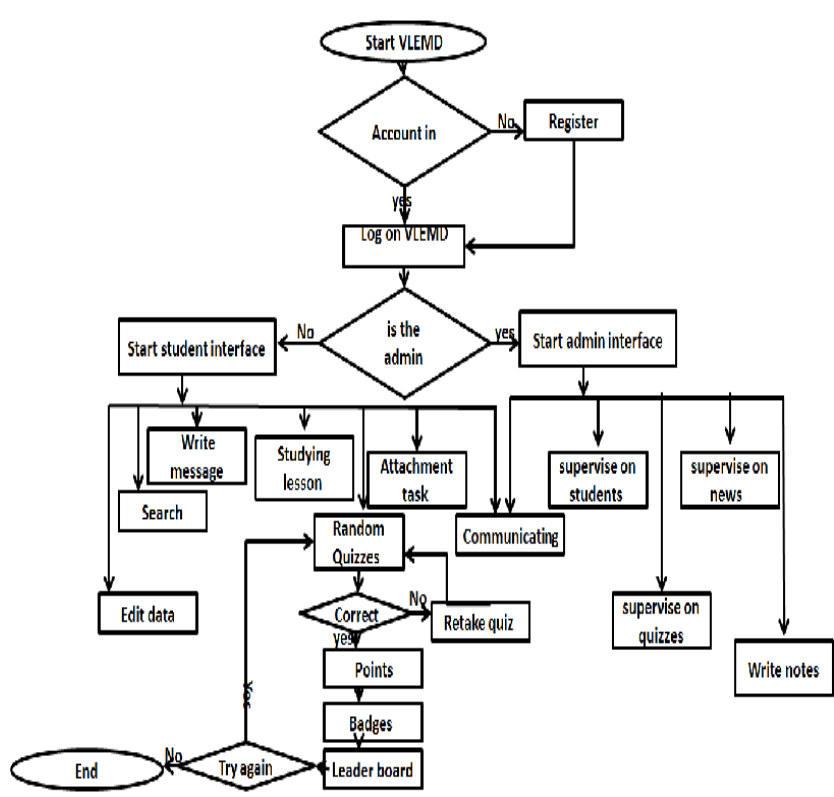

Fig. 2 The workflow of the VLEMD

\subsubsection{Roles of admins}

As shown in Figure 2, the admin's (teacher) roles are: Supervising students by adding a student, modifying student data, deleting a student, monitoring student progress, supervising news by adding, modifying or deleting news on the bulletin board, and supervising quizzes by adding, modifying or deleting a question and can display Reports about students' results in quizzes, write his notes in the notebook, and communicate with students through the forum, or e-mail or chat.

\subsection{3 student and admin login}

The VLEMD requires from admin and students to $\log$ in by entering their names and passwords in order to achieve privacy and security for the data. The password for their email accounts can be used to $\log$ in as shown in the figure 3 .

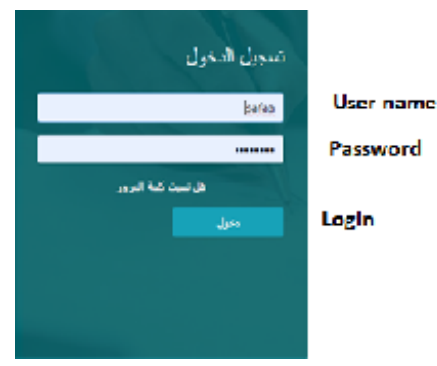

Fig.3 User login

\subsubsection{The VLEMD graphical user interface}

The VLEMD graphical user interface is designed for easyto-use interact with deaf students. It was reinforced with Arabic sign language that deaf students understand so, that they can identify the tools and functions in the learning environment. The graphical user interface consists of several areas, a top, a right, and a content area, as shown in Figure 4. The upper area contains interaction tools such as logging out, modifying data, chat room, e-mail, forum, search tool, virtual classes, educational games and helps. The right area includes the educational content such as, objectives, lessons, quizzes, results. Notebook, news board. In the middle part, a video of sign language is displayed for explain the content to the user. 


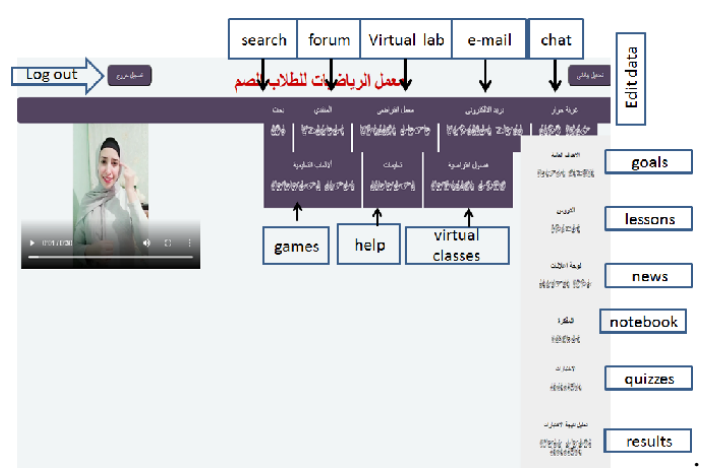

Fig. 4 The VLEMD graphical user interface

\subsubsection{Template Based Content}

The design of the lessons structure is based on content which based on the use of templates. The use of templates in the preparation of educational elements leads to a clear, organized and easy design. Using different content block templates for titles or content makes the deaf student easily distinguish the displayed content such as, definition, task, summary, exercises or solution. The content block is used to improve the reading skills of the text for the deaf students. Figure 5 shows the structure of the learning environment, which consists of four parts: header, footer, right and middle. In the right corner of the head part is a sign language video where the learners' perspective is natural, which The use of a video explaining the content of the lesson in sign language increases the motivation of the deaf towards learning. as well as tools that define control in interaction such as exit from the course, help, and communication. A special icons has been included for each functionality to identify easily by the deaf students. The, footer part displays the navigation pan between pages, and back to home. While the middle part is the learning and working area, which displays the content of the lesson. Finally, the right part displays the educational contents of the lesson, such as lesson objectives, introduction, activities, content, assignments, and tests.

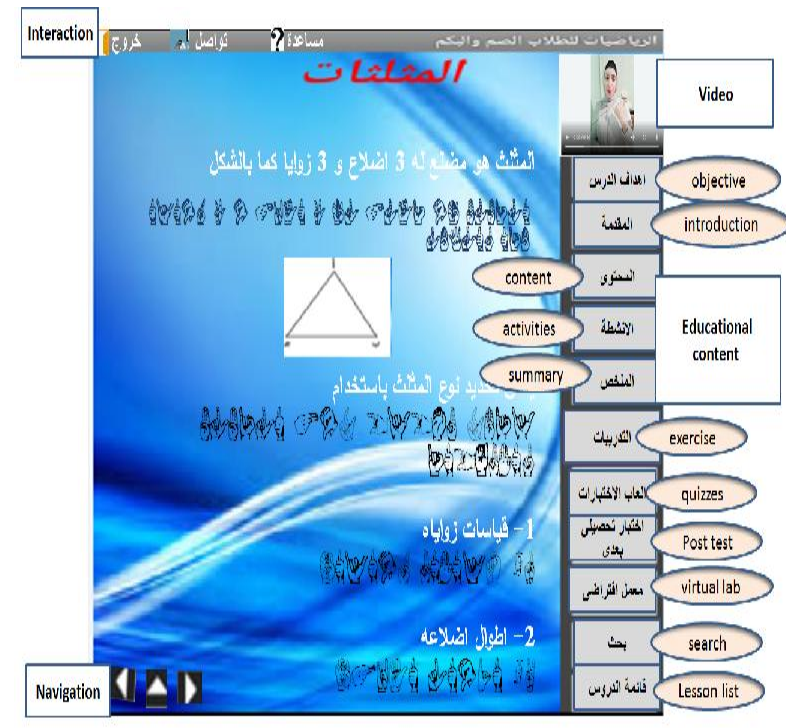

Fig. 5 Structure of the learning interface

The learning environment provides a virtual lab that enables students to draw geometric shapes such as angles and triangles of various kinds, frequently in order to gain practical skill.

\subsubsection{Gamified quizzes}

in VLEMD, Students move from one subject to another according to their personal abilities, the student can't move from one subject to another until after passing the current subject by at least $60 \%$. At the end of the course, a test is given to assess the learning outcomes. The VLEMD provides quizzes based on gamification method. To design a gamification system, several components must be taken into consideration, such as defining the player, defining the task, defining the way to motivate the player, defining the method of management and measurement [ 40].

\section{- define the player}

In this step, students are classifed based on the level they have reached in learning and their activties . The game is divided into many stages, each stage special of a specific lesson of the course. At the end of the lesson, a quizzes is performed, which begins with identifying the players participating in the current lesson, they are randomly selected from the random selection panel as in Figure 6

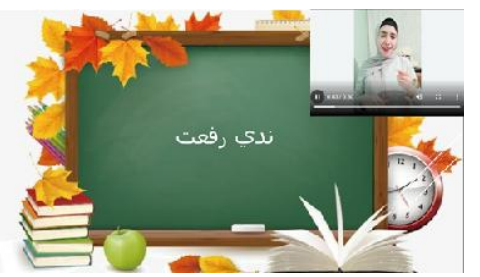

Fig. 6 the random selection panel for players

\section{- define the task}

The player performs a quiz, he answers the quiz questions. when answered correctly gets a reinforcement, which is moving the car forward a distance as in Figure 7, and gets many points recorded in the score report. When answering a question wrongly, he gets a reinforcement that the answer is wrong and no points are scored for this question.

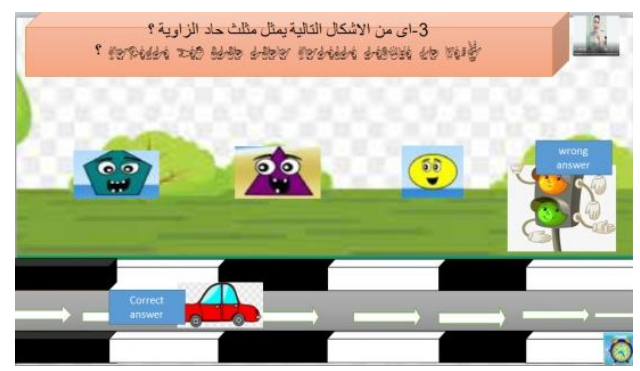

Fig7. Question with its reinforcement answers which displayed, and the design based on time

- $\quad$ define the motivates

Using badges to motivate players helps to achieve faster and smarter than competitors. Figure 8 shows some of the badges used in this quizzes. The player needs to reach a specific number of points in order to get a badge. Also, using challenges, especially with players with visual recognition, can be motivated access to higher levels. In addition to putting the player under the pressure of time and the countdown works to motivate players in facing challenges as shown in Figure 7. 


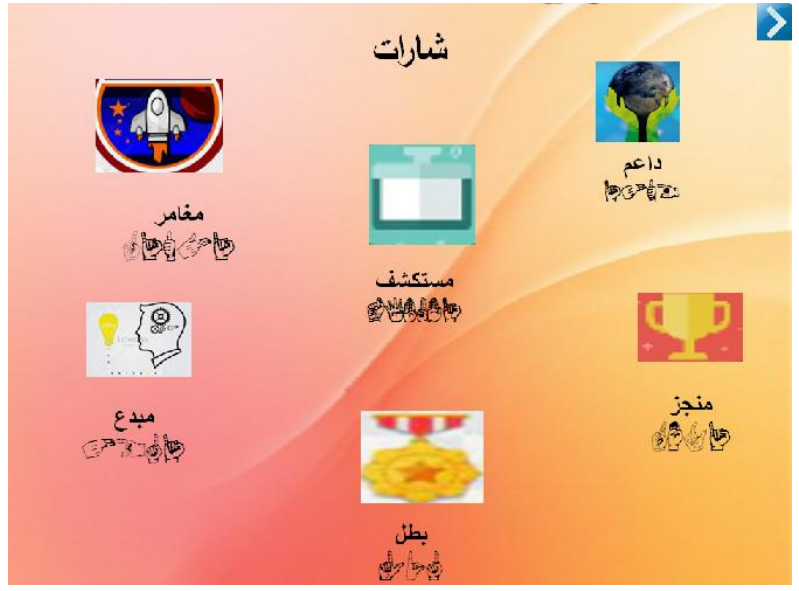

Fig. 8 Some of the badges used in the proposed quizzes

\section{- leaderboards}

Leaderboards are one of the most widely used digital game motivators, helping players to outperform their peers. It represents a list of all the participants, it displayed the ranking the participants by their performance compared with the rest of the participants in the quizzes, based on the points which they got. Figure 9 shows the design of the leaderboard in this system.

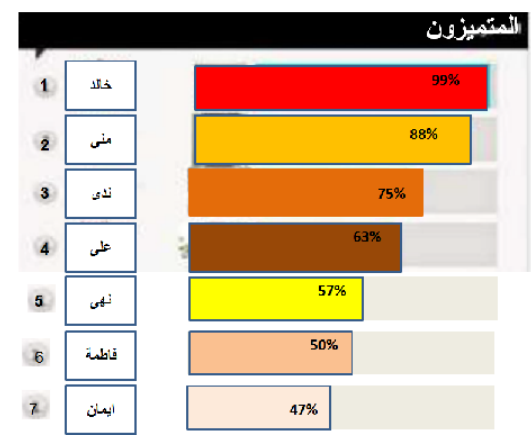

Fig. 9 Leader board

\subsubsection{The report of Learner performance}

The VLEMD provides all information about the results of the assessment of quizzes, where the student can view a detailed report about his performance in the quizzes. The report includes information such as: test performance date, time taken, lesson name, status, grade, number of points, number of unanswered questions, number of wrong answers, and number of correct answers. Figure 10 shows the student performance report.

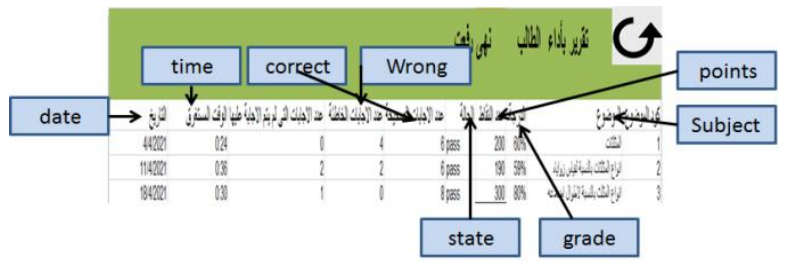

Fig. 10 The student performance report

In addition, communication tools in VLEMD provide ways for deaf students to communicate with their teacher and classmates

*The e-mail tool allows them to exchange mail messages without having to log into their personal accounts. The tool provides dealing with messages through draft, inbox and outbox, and creating a message

* The forum tool allows students to discuss topics related to learning topics by putting messages and responding on them from others

* The chat tool allows students to communicate with each other and with the teacher.

\section{EXPERIMENTAL 4.1 Participants}

the participants in this study were selected from sixth grade students in the first stage of education at Al-Amal School for the Deaf and Hard of Hearing in Damietta - Egypt. The experiment was applied to a unit of the mathematics course, which consists of six lessons: Right- triangle , acute- triangle , obtuse- triangle, equilateral triangle, isosceles triangle, scalene triangle. The experiment was implemented in a six weeks of the academic year 2020-2021. The study used an achievement test to measure the average scores of the participants in the triangles unit, it consisted of 50 multiplechoice questions, which were contained with the first three levels in Bloom's classification which they are (knowledge, comprehension and application). The practical skills test was used. After legalizing the two tests.

\subsection{Hypotheses}

The following null hypotheses are considered, at the 0.05 significance level.

H0A: There will be no significant difference $(p<0.05)$ in the average achievement scores of the experimental group students in the pre and post test of the concepts achievement test with its levels (knowledge, understanding, and application) after completing the mathematics course that uses a Virtual Learning Environment based on gamefication .

H0B: There will be no significant difference $(\mathrm{p}<0.05)$ in the average skills scores of the experimental group students in the pre and post test of the practical skills test after completing the mathematics course that uses a Virtual Learning Environment based on gamefication .

\section{RESULTS AND DISCUSSION}

This study used one experimental group and applied a pre and post test on the measurement tools. which used to verify the effects of the proposed learning environment on the achievement and performance of deaf students in mathematics. As this method allows observing the treatment of variables in order to verify the effects of the proposed learning environment. The software package spss 20 was used to analyze the data collected from the pre and post tests.

\section{First Test hypothesis 1:}

To assess the difference between the mean scores of the experimental group students in the pre and post achievement test, the t-test for correlated samples was used. As shown in Table 1, the average achievement scores for the post-test $(\mathrm{M}=$ $30.82, \mathrm{SD}=5.759)$ are much higher than for the pre-test $(\mathrm{M}=$ $11.38, \mathrm{SD}=3.943$ ). Table 1 also shows that the $\mathrm{t}$-value of the group in the pre and post test $([49, \mathrm{n}=20]=32.212, \mathrm{p}=$ 0.001 ) and this value indicates that there is a difference between the average scores of students in the pre and post achievement in favor of the post test. this indicates to the 
rejection of the null hypothesis and acceptance of the alternative hypothesis that VLEMD based on gamification is effective in increasing the achievement of deaf students in mathematics. Figure 11 shows the difference between the mean scores of the sample participating in the pre and post test of the achievement test with its three levels (knowledge comprehension - application)

Table 1 The t-test values for pr-post test for VLEMD achievement test

$\begin{array}{llllll}\text { Group } & \mathrm{M} & \mathrm{SD} & \mathrm{T} & \mathrm{DF} & \text { Sig. } \\ \text { pre } & & & & & \\ & 11.38 & 3.943 & & & \end{array}$

Post $\quad 30.82 \quad 5.759$

$* \mathrm{p}<0.05 . * * \mathrm{p}<0.01$

Differences between mean pre-and post-test scores in achevment test

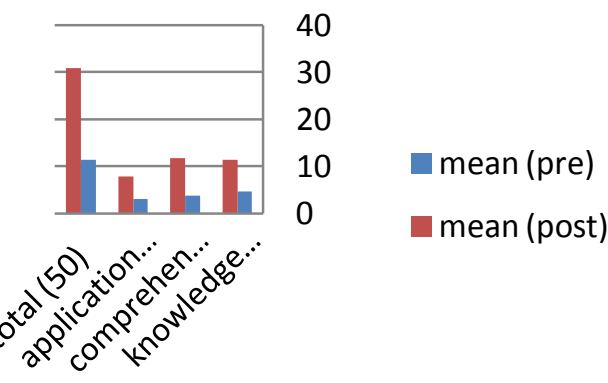

Fig. 11 mean of student score in pre and post- VLEMD for achievement test second Test hypothesis 2:

The other objective of the study is assess the mathematical skills of deaf students after applying the VLEMD based on gamefication in their learning. From Table 2, find that the means scores of students in the post-test practical skills $(\mathrm{M}=$ $30.28, \mathrm{SD}=4.759)$ are much higher $(\mathrm{M}=9.84, \mathrm{SD}=2.943)$ for the pre- test. It indicates that the use of the VLEMD based on gamefication was more effective in developing practical skills in mathematics for deaf students. Table 2 indicates the tvalues of the experimental group in the pre and post-test $t$ $([49, \mathrm{n}=20]=26.212, \mathrm{p}=0.000)$ and this indicates that there is a clear difference between the means scores of the experimental group in the pre and post application in values related to mathematical practical skills. Therefore, the null hypothesis was rejected and acceptance the alternative hypothesis related to the effectiveness of using the VLEMD based on gamefication in enhanced mathematical practical skills to deaf students.

Table 2 The t-test values for pr-post test for VLEMD based gamefication in skill test.

$\begin{array}{cccccc}\text { Group } & \text { M } & \text { SD } & \text { T } & \text { DF } & \text { Sig. } \\ \text { pre } & 9.84 & 2.943 & 26.212 & 49 & \end{array}$
Post $\quad 30.28 \quad 4.759$
0.000

$* \mathrm{p}<0.05 . * * \mathrm{p}<0.01$

\section{Differences between mean pre-and post-} test scores in skills test

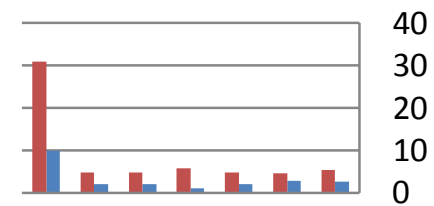

mean (pre)

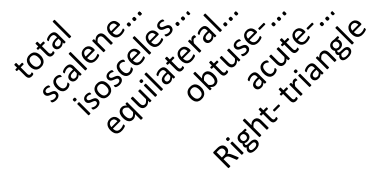

mean (post)

Fig. 12 mean of student score in pre and post- VLEMD for skills test

\section{CONCLUSIONS}

This paper proposes the development and testing of a virtual learning environment (VLEMD) based on gamification for deaf students. This environment aims to improve the achievement and skills of deaf students in mathematics. VLEMD are useful for teachers and students. The results showed the positive of the proposed system in acquiring knowledge and practical skill for deaf students in mathematics. The VLEMD has been supported by a set of tools that enable the teacher to manage learning and control students and make it more attractive and interesting for deaf students with visual awareness. Future research is needed to adapt learning environments based on gamification to increase the achievement and skills of blind students in mathematics.

\section{REFERENCES}

[1] Clark, R., \& Mayer, R. E. (2011). E-learning and the science of instruction [electronic resource]: Proven guidelines for consumers and designers of multimedia learning. San Francisco, CA: Pfeiffer.

[2] Kerr, S. J., Neale, H. R., \& Cobb, S. V. (2002). Virtual environments for social skills training: The importance of scaffolding in practice. In Proceedings of the Fifth International ACM SIGCAPH Conference on Assistive Technologies (pp. 104-110). New York, NY: ACM Press.

[3] Borba, M. C., \& Villarreal, M. E. (2005). Humans-withmedia and the reorganization of mathematical thinking: Information and communication technologies, modeling, visualization and experimentation. New York, NY: Springer Science + Business Media.

[4] Swanwick, R., Oddy, A., \& Roper, T. (2005). Mathematics and deaf children: an exploration of barriers to success. Deafness \& Education International, 7(1), 121.

[5] A. Al-Osaimi, H. AlFedaghi, and A. Alsumait, User Interface Requirements for E-Learning Program Designed for Deaf Children, First Kuwait Conf. on EServices and E-Systems, Nov 17-19, 2009.

[6] R. Howell, Case study: E-learning opportunities for deaf 
students, National VET E-learning Strategy, TAFE SA Adelaide South Institute, South Australia, 2012, Available

from:https://pfp2012.wikispaces.com/file/view/elearning _for_deaf_case_stu dy.pdf/353296994/elearning_for_deaf_case_study.pdf.

[7] Gregory, S. (1998). Mathematics and deaf children. Issues in deaf education, 119-126.

[8] Braden, J. P. (1994). Deafness, deprivation, and IQ. Springer Science \& Business Media.

[9] Bellugi, U., O’Grady, L., Lillo-Martin, D., Hynes, M. G., van Hoek, K., \& Corina, D. (1990). Enhancement of spatial cognition in deaf children. In From gesture to language in hearing and deaf children (pp. 278-298). Springer, Berlin, Heidelberg.

[10] Lang, H. G. (2002). Higher education for deaf students: Research priorities in the new millennium. Journal of deaf studies and deaf education, 7(4), 267-280.

[11] Winn, S. (2007). Employment Outcomes dor People in Australia Who Are Congenitally Deaf: Has Anything Changed?. American Annals of the Deaf, 152(4), 382390.

[12] Bucciarelli, L. L. (1996). Educating the Learning Practitioner, Invited Lecturer. In SEFI Annual Conference. Viena.

[13] Fernandez-Sanchez, P., Salaverria-Garnacho, A., Valdes, V. G., \& Mandado, E. (2011). Using a virtual laboratory as a self-assessment tool for complex technologies learning. 1st World Engineering Education Flash Week, 569-573.

[14] Jeschke, S., Pfeiffer, O., \& Richter, T. (2006, October). Integration of Virtual Laboratories in Intelligent Training Courses for undergraduate mathematics classes. In ELearn: World Conference on E-Learning in Corporate, Government, Healthcare, and Higher Education (pp. 620627). Association for the Advancement of Computing in Education (AACE).

[15] Prieto-Blázquez, J., García-Torà, I., Herrera-Joancomartí, J., \& Guerrero-Roldán, A. E. (2008, October). Virtual Laboratory ontology for engineering education. In 2008 38th Annual Frontiers in Education Conference (pp. S2F1). IEEE.

[16] Reese, S. A. (2015). Online learning environments in higher education: Connectivism vs. dissociation. Education and information technologies, 20(3), 579-588.

[17] Dillenbourg, P., Schneider, D., \& Synteta, P. (2002, September). Virtual learning environments. In Proceedings of the 3rd Hellenic conference information \& communication technologies in education (pp. 3-18).

[18] Elabnody, M., Fouad, M., Maghraby, F., \& Hegazy, A. (2017). Framework for gamification based E-learning systems for higher education in Egypt. International Journal of Intelligent Computing and Information Sciences, 17(3), 85-97.

[19] Kiryakova, G., Angelova, N., \& Yordanova, L. (2014). Gamification in education. Proceedings of 9th International Balkan Education and Science Conference.
[20] Şad, S. N., \& Özer, N. (2019). Using Kahoot! as a gamified formative assessment tool: a case study. International Journal of Academic Research in Education, 5(1), 43-57.

[21] Dicheva, D., Dichev, C., Agre, G., \& Angelova, G. (2015). Gamification in education: A systematic mapping study. Journal of Educational Technology \& Society, 18(3).

[22] Deterding, S., Dixon, D., Khaled, R., \& Nacke, L. (2011, September). From game design elements to gamefulness: defining" gamification". In Proceedings of the 15th international academic MindTrek conference: Envisioning future media environments (pp. 9-15).

[23] Chou, Y. K. (2019). Actionable gamification: Beyond points, badges, and leaderboards. Packt Publishing Ltd.

[24] Bruder, P. (2015). Game on: Gamification in the classroom. The Education Digest, 80(7), 56.

[25] Dicheva, D. (2017, June). Gamification in Education: A Passing Trend or a Genuine Potential?. In Proceedings of the 18th International Conference on Computer Systems and Technologies (pp. 11-11).

[26] Bloom, B. S. (1971). Handbook on formative and summative evaluation of student learning.

[27] Hakak, S., Noor, N. F. M., Ayub, M. N., Affal, H., Hussin, N., \& Imran, M. (2019). Cloud-assisted gamification for education and learning-Recent advances and challenges. Computers \& Electrical Engineering, 74, 22-34.

[28] Peter W. Stonebraker, and James E. Hazeltine, Virtual learning effectiveness An examination of the process, The Learning Organization, Vol. 11 No. 3, 2004, pp. 209-225, Emerald Group Publishing Limited.

[29] M. Debevc, P. Kosec, A. Holzinger, ( 2010) E-Learning Accessibility for the Deaf and Hard of Hearing Practical Examples and Experiences, USAB'10 Proceedings of the 6th international conference on $\mathrm{HCI}$ in work and learning, life and leisure: workgroup humancomputer interaction and usability engineering, SpringerVerlag Berlin, Heidelberg, , pp. 203-213.

[30] Debevc, M., Stjepanovič, Z., \& Holzinger, A. (2014). Development and evaluation of an e-learning course for deaf and hard of hearing based on the advanced Adapted Pedagogical Index method. Interactive learning environments, 22(1), 35-50.

[31] N. Adamo-Villani, E. Carpenter, and L(2006). Arns, An immersive virtual environment for learning sign language mathematics. ACM Proceedings of Siggraph Educators Program. Boston, 2006.

[32] Shohieb, S. M. (2019). A gamified e-learning framework for teaching mathematics to arab deaf students: supporting an acting Arabic sign language avatar. Ubiquitous Learning: An International Journal, 12(1), 55-70.

[33] Attali, Y., \& Arieli-Attali, M. (2015). Gamification in assessment: Do points affect test performance?. Computers \& Education, 83, 57-63.

[34] Adeniyi, S., \& Kuku, O. (2020). Impact of gamification and experiential learning on achievement in mathematics among learners with hearing impairment in Lagos State, 
Nigeria. African Journal of Educational Studies in Mathematics and Sciences, 16(2), 51-65.

[35] Chebotareva, I., Pashutina, O., \& Makhova, V. (2020, May). Digital Gamification as a Leading Factor in the Educational and Learning Process of Law Students. In 6th International Conference on Social, economic, and academic leadership (ICSEAL-6-2019) (pp. 228-234). Atlantis Press.

[36] Bidarra, J., Escudeiro, P., Escudeiro, N., Reis, R., Baltazar, A. B., Rodrigues, P., ... \& Barbosa, M. (2015). Game design and the gamification of content: assessing a project for learning sign language. In EDULEARN 2015: 7th International Conference on Education and New Learning Tecnologies. International Academy of Technology, Education and Development (IATED).

[37] Gafni, R., Achituv, D. B., Eidelman, S., \& Chatsky, T.
(2018). The effects of gamification elements in elearning platforms. Online Journal of Applied Knowledge Management (OJAKM), 6(2), 37-53.

[38] Jagušt, T., Boticki, I., Mornar, V., \& So, H. J. (2017, July). Gamified digital math lessons for lower primary school students. In 2017 6th IIAI international congress on advanced applied informatics (IIAI-AAI) (pp. 691694). IEEE.

[39] Ng, C. K., Liew, Y. T., Saripan, M. I., \& Noordin, A. F. A. N. K. (2008). Flexi E-Learning System: disabled friendly education system. Eur J Soc Sci, 7(2), 120-127.

[40] Kumar, J. (2013, July). Gamification at work: Designing engaging business software. In International conference of design, user experience, and usability (pp. 528-537). Springer, Berlin, Heidelberg. 